\title{
ANALISIS MIMO UNTUK PENINGKATAN KAPASITAS SISTEM SELULER 4G LTE PADA SISTEM KOMUNIKASI HIGH ALTITUDE PLATFORM STATION
}

\author{
Catur Budi Waluyo \\ Prodi Teknik Elektro \\ Sekolah Tinggi Teknologi Adisutjipto \\ Jl. Janti Blok R Lanud Adisutjipto Yogyakarta \\ catur_budiwaluyo $a$ yahoo.co.uk
}

\begin{abstract}
The development of technology has opened up a new wireless infrastructure to complement the satellite and terrestrial networks. High Altitude Platforms (HAPS) is a communications infrastructure that uses air balloon as a solution between terrestrial and satellite communications systems with medium coverage and low cost of launching and maintenance. HAPs can be joined with a Long Term Evolution (LTE) technology standardized by the Third Generation Partnership Project (3GPP). LTE uses orthogonal frequency division multiplexing (OFDM) technology for downlink.

OFDM technology is a technology that uses multicarrier and bring the data in parallel and the bandwidth is divided into several subcarrier. To improve the performance of LTE in an increase in capacity, coverage, and speed of data, then it can use MIMO techniques. MIMO is a technique using multiple antenna transmitter and receiver antennas that are used to overcome the problem of multipath fading and increase the capacity of the system to be serviced. MIMO support the achievement of high transmission speed.

In the simulation, signals generated by the modified jakes model into a ricean channel using the $K$ factor $1.41,1.99,2.33,2.66,4.61,6.35,9.21,12.15,16.77 \mathrm{~dB}$ with elevation angle of $10^{\circ}$ to $90^{\circ}$. The larger the $K$ factor, the smaller the shift doppler at each speed. Elevation angle have a relationship to the coverage area of HAPs, the smaller the elevation angle of the wider the coverage area, and the higher the position, the wider HAPs coverage area too. In ergodic capacity, the smaller the $K$ factor, the smaller the elevation angle so that the capacity is also greater. System without estimation for the $K$ factor of $1.41 \mathrm{~dB}$ and $K 9.21 \mathrm{~dB}$ is necessary for channel estimation and the Bit Error Rate (BER) of the same system that made channel estimation has a better performance compared with the existing channel without estimation with the SNR improvement of about $18 \mathrm{~dB}$.
\end{abstract}

Keywords: HAPs, LTE,MIMO

\begin{abstract}
Abstrak
Perkembangan teknologi telah membuka sebuah infrastruktur baru nirkabel yang digunakan untuk melengkapi jaringan satelit dan terestrial. High Altitude Platforms (HAPs) merupakan suatu infrastruktur komunikasi yang menggunakan balon udara sebagai solusi antara sistem komunikasi terestrial dan satelit dengan cakupan yang menengah, biaya peluncuran dan pemeliharaan yang rendah. HAPs dapat ditumpangi sebuah teknologi Long Term Evolution (LTE) yang distandarisasi oleh Third Generation Partnership Project (3GPP). LTE menggunakan teknologi Orthogonal Frequency Division Multiplexing (OFDM) untuk downlink.

Teknologi OFDM merupakan teknologi yang menggunakan multicarrier dan membawa data secara paralel serta dengan bandwidth yang dibagi-bagi menjadi beberapa subcarrier.Untuk meningkatkan performansi LTE dalam peningkatan kapasitas, area cakupan dan kecepatan data, maka dapat menggunakan teknik multi input multi output (MIMO). MIMO adalah teknik menggunakan beberapa antena pengirim dan antena penerima yang digunakan untuk mengatasi masalah multipath
\end{abstract}


fading dan menambah kapasitas sistem yang akan dilayani. MIMO mendukung pencapaian kecepatan transmisi yang tinggi.

Pada simulasi sinyal dibangkitkan dengan model jakes yang dimodifikasi menjadi kanal ricean dengan faktor $\mathrm{K}$ yang digunakan yaitu $1.41,1.99,2.33,2.66,4.61,6.35,9.21,12.15,16.77$ dengan sudut elevasi $10^{\circ}$ sampai $90^{\circ}$. Pada kapasitas ergodik, semakin kecil faktor K maka semakin kecil sudut elevasi sehingga kapasitasnya juga semakin besar. Sistem tanpa estimasi pada faktor K sebesar $1.41 \mathrm{~dB}$ dan $\mathrm{K}$ sebesar $9.21 \mathrm{~dB}$ perlu dilakukan estimasi kanal, karena dengan Bit Error Rate (BER) yang sama sistem yang dilakukan estimasi kanal mempunyai performansi yang lebih baik dibanding dengan tanpa ada estimasi kanal dengan perbaikan sekitar $18 \mathrm{~dB}$

Kata kunci: HAPs, LTE,MIMO

\section{Pendahuluan}

Pada perkembangan komunikasi wireless untuk menyediakan layanan data yang berkecepatan tinggi (high data rate) dan bandwidth yang lebar merupakan sebuah tantangan. Salah satu teknik untuk mewujudkannya adalah dengan menggunakan modulasi Multicarrier Orthogonal Frequency Division Multiplexing (OFDM), di mana pada OFDM efek kanal frequency selective fading akan dirasakan flat fading oleh setiap subcarrier-nya. Sistem komunikasi yang mendukung teknologi OFDM salah satunya adalah Long Term Evolution (LTE) dengan berbagai jenis konfigurasi bandwidth yang disediakan. Selain operasi bandwidth yang fleksibel, LTE mendukung peningkatan kapasitas, area cakupan, kecepatan data, latency yang rendah, multi antena, dan dapat diintegrasikan dengan sistem lain (Waluyo dan Iskandar, 2015 ; Zarrinkoub,2014; Ayadi et al,2002).

Untuk meningkatkan performansi LTE dalam peningkatan kapasitas, area cakupan dan kecepatan data, maka dapat menggunakan teknik multi antena baik di penerima maupun pengirim atau sering disebut multiple input multiple output (MIMO) (Zarrinkoub, 2014; Khalifi dan Bouallegue, 2011 ). MIMO yaitu dengan menggunakan beberapa antena pengirim dan antena penerima yang digunakan untuk mengatasi masalah multipath fading dan menambah kapasitas sistem yang akan dilayani. MIMO mendukung pencapaian kecepatan transmisi yang tinggi.

Sistem komunikasi High Altitude Platforms Station (HAPs) merupakan suatu komunikasi yang menggunakan balon udara sebagai medianya dengan jangkauan yang menengah. Ada beberapa kelebihan dari sistem komunikasi HAPs yaitu cakupan area yang luas, kapasitas yang tinggi, sudut elevasi yang besar, biaya peluncuran dan pemeliharaan yang rendah (Mohammed dan Yang, 2009; Grace dan Mohorcic, 2011). Sehingga untuk menggabungkan kelebihan dari sistem komunikasi LTE dan HAPs maka pada penelitian ini menganalisa performansi dari kanal HAPs dan kapasitas berdasarkan faktor $\mathrm{K}$ yang sudah dilakukan pengukuran oleh Iskandar and Shimamoto (2005) dengan metode Multi antena atau Multi Input Multi Output (MIMO).

\section{Metode Penelitian}

\subsection{Perkembangan Komunikasi dengan menggunakan High Altitude Platform Station}

Sistem High Altitude Platforms (HAPs) adalah pesawat atau balon udara yang bekerja di lapisan Stratosphere sekitar $20 \mathrm{~km}$. HAPs dapat digunakan untuk menyediakan layanan broadcast dan multicast serta point-to-point. Karena HAPs mempunyai kesamaan dengan satelit, berdasarkan skenario yang di pelajari oleh ETSI pada satelit di (Mohammed and Yang, 
2010; Thorton et al, 2001) juga relevan untuk HAPs. Secara khusus, HAPs dapat menyediakan jaringan lokal dan backbone, jaringan akses, termasuk akses internet, seperti konektivitas perusahaan secara intranet maupun internet dengan syarat masih dalam area jangkauannya. Untuk Perbandingan antara sistem komunikasi Terestrial, HAPs, dan layanan satelit dapat dilihat pada tabel 1 .

Tabel 1. Perbandingan komunikasi Terestrial, HAPs, dan Layanan Satelit.

\begin{tabular}{l|l|l|l}
\hline & Terestrial & \multicolumn{1}{|c}{ HAPs } & \multicolumn{1}{c}{ LEO Satclit } \\
\hline Area cakupan & $<1 \mathrm{Km}$ & sampai $200 \mathrm{Km}$ & $>500 \mathrm{Km}$ \\
\hline Ukuran Sel & $0.1-1 \mathrm{Km}$ & $1-10 \mathrm{KM}$ & $<50 \mathrm{Km}$ \\
\hline Total Arca byanan & Spot area & NasionalRegional & Gilobal \\
\hline $\begin{array}{l}\text { Kecepatan data } \\
\text { maksimum per User }\end{array}$ & $155 \mathrm{Mbps}$ & $25-155 \mathrm{Mbps}$ & $<64 \mathrm{Mbps}$ downlink \\
\hline $\begin{array}{l}\text { Penyebaran Sistem } \\
\text { Tetap }\end{array}$ & Fleksibel & Kompleks
\end{tabular}

\subsection{Perkembangan Long Term Evolution}

Menurut (Zarrinkoub, 2014) pada tahun 2001 Universal Mobile Telecommunication System (UMTS) dirilis dengan data rate downlink $1.92 \mathrm{Mbps}$ dan di upgrade ke High Speed Downlink Packet Access (HSDPA) dengan data rate yang ditawarkan 14.4 Mbps menggunakan subframe lebih pendek dan modulasi 16-QAM (Quadrature Amplitude Modulation). Kemudian dirilis standar baru HSDPA dengan Multi Input Multi Output (MIMO) $2 \times 2$ modulasi 64-QAM data rate mencapai $84 \mathrm{Mbps}$.

Pada LTE satu subframe terdiri dari 2 slot, masing-masing satu slot sebesar $0.5 \mathrm{~ms}$ yang terdiri dari 7 simbol. Satu slot terdiri dari 8192 sampel dengan nomal cyclic prefix (asumsi frekuensi sampel 15,36 MHz). Untuk ilustrasi Cell Specific Reference (CSR) dapat dilihat pada gambar 1 .

Pada kanal ricean, terdapat kontribusi dari komponen LOS (line of sight) dan komponen non-LOS (kontribusi dari kanal Rayleigh). Untuk model kanal rician yang dinormalisasi (Waluyo dan Iskandar, 2015) dapat dilihat pada persamaan 1.

$$
H_{\text {ric }}=a H_{L O S}+b H_{R a y}=\sqrt{\frac{K}{K+1}} H_{L O S}+\frac{1}{\sqrt{K+1}} H_{R a y}
$$

Menurut (Zaskia dll, 2011) untuk menghitung penguatan multiplexing banyak pengguna dapat didefinisikan pada persamaan 2 .

$$
\operatorname{Mux}_{\text {gain }}=\frac{C}{\log _{2}\left(10^{\text {SNR/10 }}\right)}
$$

Di mana $\mathrm{C}$ adalah kapasitas yang dinormalisasi pada grafik jumlah laju kapasitas (bits $/ \mathrm{s} / \mathrm{Hz}$ ), SNR adalah signal to noise ratio $(\mathrm{dB})$. Dengan melihat hubungan $\mathrm{K}$ sebagai perbandingan daya LOS dan daya scattering serta sudut elevasi pada frekuensi $2.4 \mathrm{GHz}$ yang sudah dilakukan pengukuran oleh (Iskandar dan Shimamoto,2005) maka dapat disajikan dalam bentuk tabel 2 . 
Tabel 2. Hubungan faktor K dan sudut elevasi pada kanal komunikasi HAP (Iskandar and Shimamoto, 2005)

\begin{tabular}{|c|c|c|c|c|c|c|c|c|c|}
\hline Sudut elevasi & $10^{\circ}$ & $20^{\circ}$ & $30^{\circ}$ & $40^{\circ}$ & $50^{\circ}$ & $60^{\circ}$ & $70^{\circ}$ & $80^{\circ}$ & $90^{\circ}$ \\
\hline Faktor K (dB) & 1.41 & 1.99 & 2.33 & 2.66 & 4.61 & 6.35 & 9.21 & 12.15 & 16.77 \\
\hline
\end{tabular}

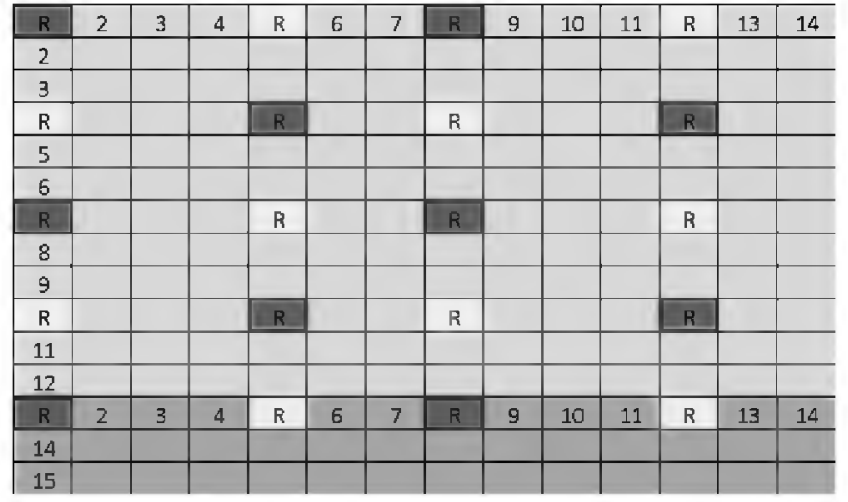

Gambar 1 Sinyal CSR LTE dengan MIMO 2×2

\subsection{Multi Antena}

Pada sistem komunikasi, kapasitas data akan berbanding terbalik dengan kecepatan data, sehingga untuk mengatasi hal ini, maka diperlukan metode multi antena baik di pengirim maupun di penerima atau sering disebut multi input multi output (MIMO). Secara umum, transmisi multi antena mengirimkan simbol data ke beberapa antena pengirim maupun diterima dengan beberapa antena penerima (Tse and Viswanath, 2005).

Pada komunikasi multi antena mempunyai kelebihan yaitu meningkatkan kapasitas sistem dan efisiensi spektral serta mengurangi efek dari fading untuk menambah diversitas, karena ketika kanal yang berbeda maka fading bersifat independen. Kapasitas dari sistem wireless akan meningkat sesuai dengan jumlah antena pengirim dan antena penerima. Dengan menggunakan Teknik Spasial Multiplexing kecepatan data akan meningkat tanpa membutuhkan frekuensi tambahan dan total daya pancar (Jiang and Hanzo, 2007).

\section{Hasil dan Pembahasan}

\subsection{Hubungan Faktor K dengan Kapasitas pada MIMO $2 \times 2$}

Pada sistem komunikasi nirkabel jumlah antena yang digunakan baik di pengirim maupun di penerima mempengaruhi kapasitas dari sistem. Pada penelitian ini antena yang digunakan yaitu 2 antena pengirim dan 2 antena penerima karena pada sistem MIMO $2 \times 2$ mempunyai kapasitas lebih besar dibandingkan pada sistem Single Input Single Output (SISO), Multi Input Single Output (MISO), Single Input Multi Output (SIMO). Untuk ilustrasi perbandingan kapasitas multi antena yang digunakan dapat dilihat pada gambar 2 .

Pada sistem komunikasi HAPs, pada kanal ricean terdapat hubungan faktor K dan sudut elevasi sesuai penelitian (Waluyo dan Iskandar,2015). Semakin kecil sudut elevasi maka kapasitas yang dilayani semakin banyak, tetapi semakin kecil sudut elevasi maka BER juga semakin besar. Untuk hubungan antara faktor $\mathrm{K}$ dan kapasitas pada kanal fading ricean yang independent and identically distributed (i.i.d) dapat dilihat pada gambar 3. Berdasarkan hasil simulasi pada gambar 3 maka hubungan antara faktor $\mathrm{K}$ dan kapasitas (dalam bps/Hz) dapat disajikan dalam bentuk tabel 3 . 
Berdasarkan pada tabel 3 pada saat sudut elevasi $10^{\circ}$ atau faktor $\mathrm{K}=1.41 \mathrm{~dB}$ dengan SNR 10dB, kapasitas ergodik sebesar $6.80 \mathrm{bit} / \mathrm{s} / \mathrm{Hz}$. Kapasitas tersebut menurun seiring pertambahan faktor $\mathrm{K}$ atau sudut elevasi HAPs yaitu menjadi $6.21 \mathrm{bit} / \mathrm{s} / \mathrm{Hz}$ dan $5.51 \mathrm{bit} / \mathrm{s} / \mathrm{Hz}$ pada saat sudut elevasi $60^{\circ}(\mathrm{K}=6.35 \mathrm{~dB})$ dan sudut elevasi $90^{\circ}(16.77 \mathrm{~dB})$ pada $\mathrm{SNR}$ yang sama. Sehingga semakin kecil sudut elevasi atau semakin kecil faktor K maka kapasitas yang dilayani juga semakin banyak.

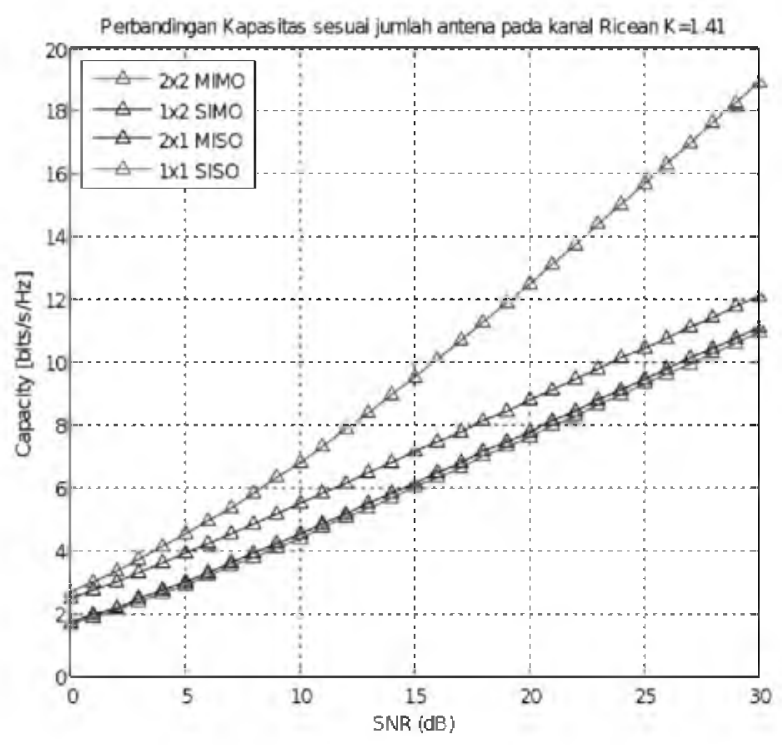

Gambar 2. Perbandingan kapasitas pada multi antena.

Berdasarkan jumlah laju kapasitas dari tabel tabel 3 pada kondisi kanal fading rician i.i.d maka dapat dihitung penguatan multiplexing dari banyak user dengan persamaan 2 . Misalkan, untuk sudut elevasi 10 dengan $\mathrm{SNR}=30 \mathrm{~dB}$ dan $\mathrm{C}=18.96 \mathrm{bit} / \mathrm{s} / \mathrm{Hz}$ maka penguatan multiplexing dari banyak user (jumlah penerima yang dilayani) yaitu:

$$
\text { Mux }_{\text {gain }}=\frac{18.96}{\log _{2}\left(10^{30 / 10}\right)} \approx 1.9
$$

Jika antena pemancar yang digunakan $(n T x)$ berjumlah 2, maka kapasitas pada SNR yang tinggi dapat dilakukan pendekatan persamaan $C \approx n R x \log _{2}(S N R)$ yang artinya bahwa kapasitas dalam sistem komunikasi HAPs dipengaruhi oleh jumlah antena yang digunakan. Kurva cumulative distribution function (CDF) dapat digunakan untuk memberikan informasi tentang kapasitas outage sebagai fungsi laju informasi kanal. Kurva CDF pada kapasitas ergodik dengan SNR yaitu $20 \mathrm{~dB}$ dapat dilihat pada gambar 4 
Catur Budi Waluyo

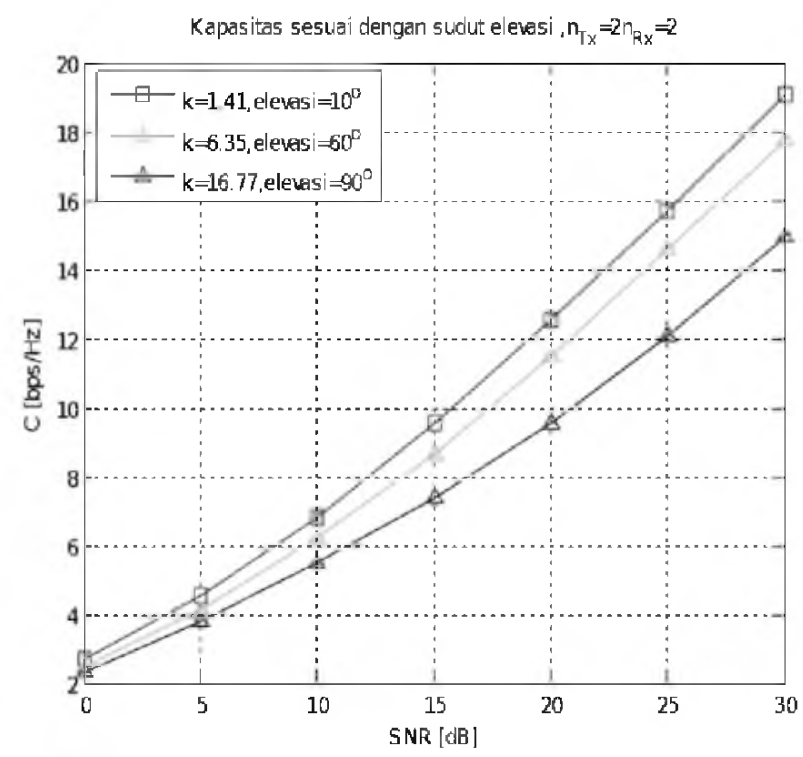

Gambar 3. Hubungan antara faktor $\mathrm{K}$ dan kapasitas pada kanal fading ricean yang independent and identically distributed (i.i.d)

Tabel 3. Hubungan antara faktor $\mathrm{K}$ dan kapasitas (dalam $b p s / H z$ ) pada sistem komunikasi HAPs

\begin{tabular}{|c|c|c|c|c|c|c|c|c|c|c|}
\hline \multicolumn{2}{|c|}{ Sudut elevasi } & $10^{\circ}$ & $20^{\circ}$ & $30^{\circ}$ & $40^{\circ}$ & $50^{\circ}$ & $60^{\circ}$ & $70^{\circ}$ & $80^{\circ}$ & $90^{\circ}$ \\
\hline \multicolumn{2}{|c|}{ Faktor $\mathrm{K}(\mathrm{dB})$} & 1,41 & 1,99 & 2,33 & 2,66 & 4,61 & 6,35 & 9,21 & 12,15 & 16,77 \\
\hline \multirow{7}{*}{$\frac{\widehat{m}}{\frac{\tilde{m}}{2}}$} & 0 & 2,72 & 2,69 & 2,66 & 2,64 & 2,58 & 2,51 & 2,43 & 2,39 & 2,34 \\
\hline & 5 & 4,58 & 4,50 & 4,47 & 4,44 & 4,32 & 4,16 & 4,01 & 3,90 & 3,82 \\
\hline & 10 & 6,80 & 6,75 & 6,72 & 6,66 & 6,42 & 6,21 & 5,93 & 5,72 & 5,51 \\
\hline & 15 & 9,44 & 9,45 & 9,47 & 9,35 & 9,05 & 8,67 & 8,23 & 7,83 & 7,37 \\
\hline & 20 & 12,51 & 12,38 & 12,36 & 12,22 & 11,97 & 11,55 & 10,88 & 10,27 & 9,51 \\
\hline & 25 & 15,76 & 15,61 & 15,56 & 15,43 & 15,00 & 14,56 & 13,85 & 13,14 & 12,05 \\
\hline & 30 & 18,96 & 18,88 & 18,72 & 18,72 & 18,25 & 17,74 & 16,89 & 16,28 & 14,93 \\
\hline
\end{tabular}

Berdasarkan gambar 4 kapasitas ergodik ditunjukkan oleh nilai tengah dari kurva CDF. Kapasitas outage jika dalam persamaan peluang sebesar $\mathrm{p} \%$ maka rate informasi yang mampu dijamin pada realisasi kanal sebesar $(100-p) \%$. Kapasitas outage dinyatakan dengan $\mathrm{p}\left(\mathrm{C} \leq \mathrm{C}_{\text {out }}\right)$. Dimisalkan $\mathrm{p}\left(\mathrm{C} \leq \mathrm{C}_{\text {out }}\right)$ sebesar $10 \%$ maka sistem dapat dikatakan mempunyai kehandalan sebesar $1-p\left(C \leq C_{\text {out }}\right)$ atau sebesar $90 \%$. Sehingga berdasarkan gambar 4 kapasitas outage untuk masing-masing faktor K berturut-turut $1.41 \mathrm{~dB}, 6.35 \mathrm{~dB}$, dan $16.77 \mathrm{~dB}$ yaitu $10.3 \mathrm{bps} / \mathrm{Hz}, 9.58 \mathrm{bps} / \mathrm{Hz}$ dan $8.75 \mathrm{bps} / \mathrm{Hz}$. 


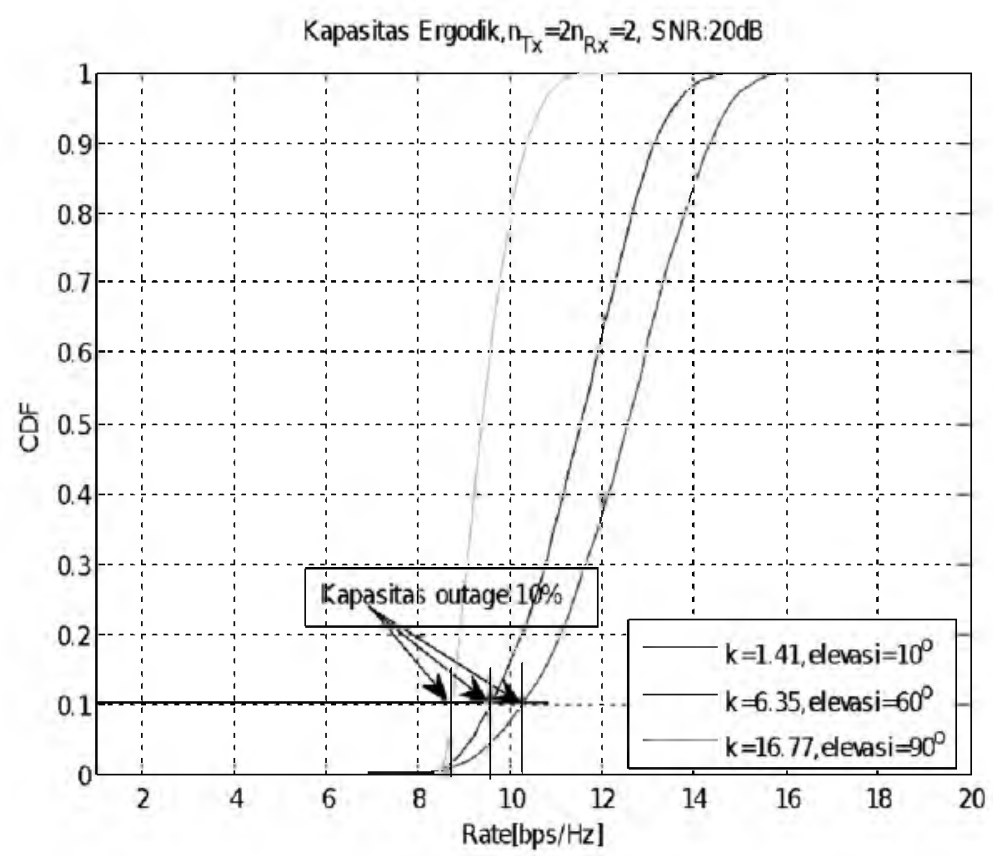

Gambar 4. CDF rate informasi MIMO $2 \times 2$ pada SNR $10 \mathrm{~dB}$.

\subsection{Hubungan MIMO dengan BER}

Dengan melihat hubungan faktor $\mathrm{K}$, sudut elevasi dan estimasi kanal maka dapat dilihat perbandingan kurva BER dengan faktor K yang kecil (sudut elevasi $10^{\circ}$ ) dan faktor K yang besar (sudut elevasi $90^{\circ}$ ) serta perbandingan antara sistem dengan dilakukan estimasi kanal dan tanpa dilakukan estimasi kanal. Untuk hasil simulasi dengan modulasi QPSK dan kecepatan kereta $30 \mathrm{~km} / \mathrm{jam}$ dapat dilihat kurva BER terhadap SNR pada gambar 5 .

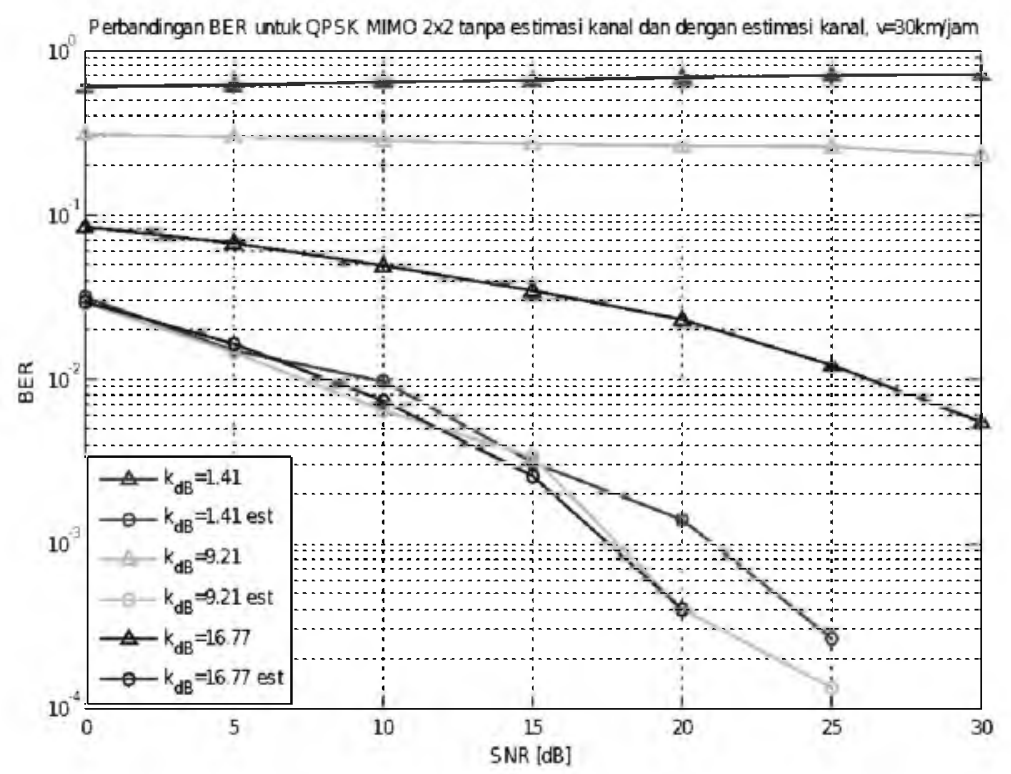

Gambar 5. Perbandingan BER MIMO $2 \times 2$ dengan dilakukan estimasi kanal dan tanpa estimasi kanal. 
Berdasarkan gambar 5 dapat dilihat bahwa dengan penambahan faktor $\mathrm{K}$ dan sudut elevasi yang kecil $\left(\mathrm{K}=1.41 \mathrm{~dB}\right.$, sudut elevasi $10^{\circ}$ maka kurva BER yang dihasilkan lebih jelek dibandingkan dengan faktor $\mathrm{K}$ dan sudut elevasi yang besar. Misalnya, pada SNR $30 \mathrm{~dB}$ dengan faktor $\mathrm{K}(\mathrm{K}=1.41 \mathrm{~dB})$ menghasilkan BER sekitar $5 \times 10^{-1}$ sedangkan dengan faktor $\mathrm{K}$ $(\mathrm{K}=16.77 \mathrm{~dB})$ menghasilkan BER sekitar $4 \times 10^{-3}$.

Pada gambar 5 juga dapat dilihat perbandingan hasil simulasi sistem dengan estimasi kanal dan tanpa estimasi kanal pada modulasi QPSK dan kecepatan kereta $30 \mathrm{~km} / \mathrm{jam}$. Misalnya, pada SNR sebesar $25 \mathrm{~dB}$ dan faktor K sebesar $1.41 \mathrm{~dB}$ maka dilihat bahwa BER yang dihasilkan pada sistem yang di estimasi lebih kecil dibandingkan pada sistem tanpa estimasi dengan nilai $1.5 \times 10^{-4}$ ( dengan estimasi) dan $6 \times 10^{-1}$ (tanpa estimasi).

Sedangkan pada SNR yang sama $25 \mathrm{~dB}$ dan faktor K sebesar $16.77 \mathrm{~dB}$ menghasilkan BER sebesar $0.5 \times 10^{-4}$ (dengan estimasi) dan $0.2 \times 10^{-2}$. Dengan demikian, sistem tanpa estimasi pada faktor $\mathrm{K}$ sebesar $1.41 \mathrm{~dB}$ dan $\mathrm{K}$ sebesar $9.21 \mathrm{~dB}$ perlu dilakukan estimasi kanal dan dengan BER yang sama sistem yang dilakukan estimasi kanal mempunyai performansi yang lebih baik dibanding dengan tanpa ada estimasi kanal dengan perbaikan BER sekitar 18 $\mathrm{dB}$.

\section{Kesimpulan}

Pada kondisi ergodik, kapasitas menurun seiring pertambahan faktor $\mathrm{K}$ yang ekivalen dengan sudut elevasi HAP yaitu menjadi $6.21 \mathrm{bit} / \mathrm{s} / \mathrm{Hz}$ dan $5.51 \mathrm{bit} / \mathrm{s} / \mathrm{Hz}$ pada saat sudut elevasi $60^{\circ}(\mathrm{K}=6.35 \mathrm{~dB})$ dan sudut elevasi $90^{\circ}(16.77 \mathrm{~dB})$ pada SNR yang sama. Sehingga semakin kecil sudut elevasi atau semakin kecil faktor $\mathrm{K}$ maka kapasitas yang dilayani juga semakin banyak. Sistem tanpa estimasi pada faktor K sebesar $1.41 \mathrm{~dB}$ dan K sebesar $9.21 \mathrm{~dB}$ perlu dilakukan estimasi kanal dan dengan BER yang sama sistem yang dilakukan estimasi kanal mempunyai performansi yang lebih baik dibanding dengan tanpa ada estimasi kanal dengan perbaikan BER sekitar $18 \mathrm{~dB}$.

\section{Ucapan Terima Kasih}

Penulis ingin mengucapkan terima kasih dan penghargaan yang setinggi-tingginya kepada Kopertis $\mathrm{V}$ atas bantuan dana penelitian (DIPA) yang diberikan sehingga penelitian ini dapat terlaksana dengan baik.

\section{Daftar Pustaka}

,2010, 3rd Generation Partnership Project, Technical Specification Group Radio Access Network, Evolved Universal Terrestrial Radio Access (E-UTRA), Physical Channels and Modulation (Release 9), 3GPP TS 36.211 V9.1.0.

Ayadi,J.,Hutter, A.A,Farserotu,J. “On the multiple Input Multiple Output capacity of Ricean Channels". 0-7803-7442-8/02. 2002. IEEE

Choo, Y.s., Yang,J. K. W. Y.,Kang, C. G., MIMO-OFDM wireless communications with matlab. John Wiley \& Sons( Asia) Ltd .2010

Grace,D. and Mohorcic,M., "Broadband Commnucation via High Altitude Platform". John wiley \& sons Ltd, 2011.UK 
Irma Zakia, Suhartono Tjondronegoro, Iskandar, Adit Kurniawan. "Sum Rate Capacity of Multiuser MISO Designed for HAPS High Speed Train Application". 2011 International Conference on Electrical Engineering and Informatics 17-19 July 2011, Bandung, Indonesia. IEEE. 2011

Iskandar, and Shimamoto,S., The channel characterization and performance evalution of mobile Communication Employing Stratospheric Platform, IEEE, 2005

Khalifi,A.H.and Bouallegue,R., 2011. Performance Analysis LS and LMMSE Channel Estimation Techniques for LTE Downlink System. International Journal of Wireless \& Mobile Networks( IJWMN). Vol 3. No 5. Oktober 2011

Mohammed,A.and Yang,Z., "Broadband Communications and Applications from High Altitude Platforms," International Journal of Recent Trends in Engineering, Vol 1, No. 3, May 2009.

Mohammed,A. and Yang,Z.. "Next Generation Broadband Services from High Altitude Platforms". IGI Global . 2010.

Rappaport,T.S., "Wireless Communications Principles and practice second edition", Prentice Hall Communications Engineering and Emerging Technologies Series,2010

Thorton,J., Grace,D., Spillard,C., T.konefal and T.C. Tozer, "Broadband communication from High Altitude Platforms: the european Helinet programme" Electronic \& communication Engineering jornal june 2001

Waluyo,C.B and Iskandar, Performance analysis with LMMSE for MIMO LTE on the High Altitude Platform Station, Pages: 308 - 313, DOI: 10.1109/ICEEI.2015.7352516, IEEE.2015

Zarrinkoub,H., "Understanding LTE with matlab from Mathematical modeling to simulation and protyping". John wiley \& sons Ltd. 2014. 
Catur Budi Waluyo 